\title{
PRINCIPLES OF ACCOUNTS
}

H. F. HEMSTOCK, B.Sc.(Lond.), Head of the Department of Commerce, Kilburn Polytechnic.

An elementary course for pupils preparing for the G.C.E. examination in Arithmetic and Accounts, or Book-keeping or Principles of Accounts. Also similar first examinations by the R.S.A. and other public examining bodies.

$7 s$.

\section{MATHEMATICS FOR MODERN SCHOOLS}

T H. WARD HILL, M.A., Dulwich College.

"An attractive and stimulating series. The books follow the modern custom of presenting the unity of mathematics by refraining from separating it into various branches which demand independent treatment there is obvious throughout an attempt to bring mathematics into close relationship with everyday life." -The Times Educationa I Supplement. Books I, 3 \& 4, 6s. each. Book 2, 6s. 6d.

\section{EXERCISES IN ELEMENTARY MATHEMATICS}

K. B. SWAINE, M.A., Yeovil School.

This course has been planned to conform with the alternative syllabus for Mathematics for the General Certificate of Education. "Should interest all teachers of the early stages of mathematics, whether in the grammar, modern junior or technical school, for no pupil who has worked through this course . . can fail to have anything but a very useful and aesirable foundation upon which to build, whatever be the later developments and requirements by the pupil."-Mathematical Gazette. Book I, 5s. 6d. Book 2, 6s. Book 3, 7s. 6d. Book 4, 8s. 6d. Answers to Book 4, 3s. 6d. Teacher's Book, 3s. 6d.

\section{A COURSE IN GEOMETRY}

J. L. LATIMER, M.A., Headmaster, Goole Grammar School, and T SMITH, B.Sc., Manchester Grammar School.

In this revised edition-the first ran to thirteen impressions -numerous diagrams have been revised in the light of modern methods of teaching and an index added. "As a whole this deductive course makes an excellent impression." -Mathematical Gazette. 6s. 6d. with answers. 6s. without answers.

\section{GEORGE G. HARRAP \& CO. LTD 182 High Holborn London W.C.I}




\title{
An Analytical Calculus (III)
}

\section{E. A. MAXWELL}

The third part of Dr Maxwell's new course designed to bridge the gap between the sixth form and the university. The present volume treats of the theory of functions of more than one variable and is suitable for first year undergraduates.

15s. net

\section{Logarithmetica Britannica}

\section{A. J. THOMPSON}

A standard table of logarithms to twenty places of the numbers 10,000-100,000 prepared for the Department of Statistics at University College London to commemorate the tercentary of Henry Brigg's Arithmetica Logarithmica of 1624. The tables, issued in parts, are now complete and are available in two bound volumes. Volume I: 10,000-50,000. Volume II: 50,000100,000 .

\section{Biometrika Tables for Statisticians}

\author{
E. S. PEARSON \& A. O. HARTLEY
}

A complete recasting of the two volumes of Tables for Statisticians and Biometricians has been undertaken by Professor Pearson and Dr Hartley. This first volume contains 12 of the most commonly used tables from the earlier volumes, 26 tables published subsequently in Biometrika and 16 tables freshly compiled and drawn from other sources.

25s. net

\section{CAMBRIDGE UNIVERSITY PRESS}

BENTLEY HOUSE, 200 EUSTON ROAD, LONDON, N.W.1 


\section{ELEMENTARY MATHEMATICS}

By C. G. NOBBS, Second Master at City of London School and author of

\section{Elementary Calculus and Co-ordinate Geometry}

BooK I. With detachable answers. 336 pages with diagrams 9 s. $6 d$. This is the first of a series of four books to cover mathematics up to Ordinary Level. The usual elementary work of arithmetic, algebra, geometry and trigonometry, and the basic principles of calculus are included, but the work is presented, as far as possible, as an organic whole. This coherence, together with the frequent references to history, the appeal to authoritative sources for the data of many examples, and the suggestions for practical work, gives a close-to-life atmosphere to the whole course.

Exercises are numerous and straightforward and revision has been tackled in a new way.

Book II should be ready in November.

\section{MODERN SCHOOLS MATHEMATICS}

By E. J. JAMES, Lecturer in Mathematics at Redland Training College, Bristol

BOOK I. 128 pages. $5 \mathrm{~s}$. Ready in October BOOK II. 128 pages: approx. 5s. Ready in December BOOKS III AND IV. In preparation

The aim is to develop the subject at a pace suitable for the B Stream but to provide opportunities for extension to meet the needs of more able children. Suggestions for doing this will be contained in a companion teachers' book.

Exercises are short so that children can experience a sense of achievement by completing them. Mathematical and computational difficulties do not occur at the same time. A bold attempt has been made to develop a sense of basic mathematical principles as well as of the application of mathematics in everyday situations. The interpretation and construction of graphical methods of conveying information are introduced early. The very early stages of algebra and geometry are used to increase the pupil's understanding of the mathematical content of the course. Drill examples, carefully graded and arranged for testing purposes, are included.

Applications for inspection copies should be addressed to

\section{OXFORD UNIVERSITY PRESS EDUCATION DEPARTMENT OXFORD}

